\title{
EVIDÊNCIAS DA PRÁTICA DE GERENCIAMENTO DE RESULTADOS: UMA ANÁLISE DAS FINTECHS BRASILEIRAS
}

\author{
EVIDENCES OF THE EARNINGS MANAGEMENT \\ PRACTICE: AN ANALYSIS OF BRAZILIAN FINTECHS
}

\section{Willian Diehl}

Mestre em Controladoria e Contabilidade pela Universidade Federal do Rio Grande do Sul (Porto Alegre/Brasil). Contador (São Sebastião do Caí/Brasil).

E-mail: willian.diehl@hotmail.com

\section{Romina Batista de Lucena de Souza}

Doutora em Economia pela Universidade Federal do Rio Grande do Sul (Porto Alegre/Brasil). Professora do Programa de Pós-Graduação em Controladoria e Contabilidade da Universidade Federal do Rio Grande do Sul (Porto Alegre/Brasil).

E-mail: rominabls@gmail.com

\section{Edilson Paulo}

Doutor em Controladoria e Contabilidade pela Universidade de São Paulo (São Paulo/Brasil).

Professor na Universidade Federal de Santa Catarina (Florianópolis/Brasil).

E-mail: e.paulo@uol.com.br

\section{Dante Baiardo Cavalcante Viana Junior}

Doutorando em Management, Specialization in Accounting pelo Instituto Universitário de Lisboa (Lisboa/Portugal). Bolsista do Instituto Universitário de Lisboa (Lisboa/Portugal).

E-mail: dantebcviana@gmail.com 


\section{RESUMO}

O Gerenciamento de Resultados (GR) é uma das diversas dimensões da qualidade da informação contábil e apresenta circunstâncias diferenciadas para cada tipo de usuário das demonstrações financeiras. O GR é caracterizado pelas modificações intencionais nos resultados contábeis. Para a economia, as FinTechs são consideradas companhias que oferecem riscos ao sistema financeiro, por apresentarem ferramentas mais "ousadas" do que as Instituições Financeiras clássicas. Assim, o objetivo desta pesquisa é analisar as evidências da prática do GR nas FinTechs brasileiras, no período de 2009 a 2017. A pesquisa classifica-se como quantitativa, descritiva e documental, aplicando regressão linear múltipla com dados em painel. Como resultados, destacase que possivelmente existem evidências da prática de GR pelos gestores das companhias classificadas como FinTechs, por meio do uso das Provisões para Perdas de Créditos (PPC). A ocorrência da prática de GR por estas companhias pode estar sendo utilizada para eficiência da companhia, onde os gestores buscam conter a volatilidade dos resultados contábeis, o que consequentemente tende a despertar menor interesse pelos reguladores e, portanto, esta prática nem sempre é realizada com propósitos oportunistas. Por fim, este estudo contribui para o meio profissional demonstrando aos diversos usuários da informação contábil, principalmente aos acionistas das FinTechs, que a prática de GR não é prejudicial à companhia, quando as escolhas são feitas legalmente.

Palavras-chave: Gerenciamento de resultados. Qualidade da informação contábil. Fintechs. Instituições financeiras.

\section{ABSTRACT}

The Earnings Management (EM) is one of several accounting information quality dimension and has different circumstances for each type of financial statements user. The EM is characterized by intentional changes in earnings accounting. For the economy, FinTechs are considered companies that offer risks to the financial system, as they present more "daring" tools than the classic Financial Institutions. Thus, the objective of this study is to analyze the evidence of EM practice in Brazilian FinTechs, from 2009 to 2017. The research is classified as quantitative, descriptive and documentary, applying multiple linear regression with panel data. As a results, it stands out that possibly there is evidence of EM practice, by companies managers classified as FinTechs, through the use of Loan Loss Provisions (LLP). The occurrence of EM practice by these companies, may be used for company efficiency, where managers seek to contain the accounting results volatility, which consequently tends to arouse less interest by regulators and therefore, this practice is not always performed with opportunistic purposes. Finally, this study contributes to the professional environment demonstrating to the various accounting information users, especially FinTechs shareholders, that the EM pratice is not harmful to the company, when the choices are made legally.

Keywords: Earnings management. Accounting information quality. Fintechs. Financial Instituions. 


\section{INTRODUÇÃO}

A qualidade da informação contábil se modifica à medida em que surgem as necessidades dos usuários da informação contábil, reproduzindo características específicas para cada tipo de usuário. Assim, submetendo-se às condições do ambiente econômico, político e social (DECHOW; SCHRAND, 2004). O Gerenciamento de Resultados (GR) é um dos diversos aspectos da qualidade da informação contábil e caracteriza-se pela manipulação intencional na elaboração das demonstrações financeiras disponibilizadas aos usuários, visando atender à objetivos particulares dos gestores, o que acaba por não representar de forma fidedigna a imagem da companhia (MARTINEZ, 2001; SCHIPPER, 1989).

Nas Instituições Financeiras (IF) a prática do GR é comumente evidenciada pelo reconhecimento da Provisões para Perdas de Crédito (PPC), demonstrando resultados constantes ao longo dos períodos e apresentando resultados com menor volatilidade, evitando a proximidade com riscos. O GR é evidenciado em diversas pesquisas da área (ARAÚJO; LUSTOSA; PAULO, 2018; ELNAHASS; IZZELDINB; STEELEB, 2018; SOUSA; BRESSAN, 2018; LASSOUED; ATTIA; SASSI, 2018). Com o surgimento das FinTechs (Financial Technology), as IF empenham-se em atingir a eficácia na adaptação e na busca pelos benefícios gerados à população pelas FinTechs, necessitando de um plano claro para esse fim (BOSHKOV, 2018). Destaca-se que o setor bancário é visto como mais "conservador" no que diz respeito às mudanças, assim, as FinTechs aparentam ser mais "ousadas". Essa característica de "ousadia" das FinTechs, é explicada pelas rápidas mudanças ocorridas nas tecnologias, as quais requerem novas soluções de imediato, preenchendo a lacuna deixada pelos bancos.

Na pesquisa de Ferreira et al. (2019), os autores buscaram compreender as evoluções de novos modelos de negócios no mercado financeiro em relação ao crédito, a partir das três maiores FinTechs, buscaram identificar o comportamento dos clientes diante dos novos modelos. Nos resultados, apresentaram que os clientes respondem de forma positiva aos novos modelos de negócios, considerando um aumento considerável de usuários em um curto espaço de tempo. Enquanto os bancos tradicionais, com agências físicas, expressam indícios de redução de clientes.

No estudo de Barbosa (2018), buscou-se examinar a forma de atuação das FinTechs no ambiente financeiro. Como resultados, evidencia-se que na atuação das FinTechs são utilizadas principalmente bases tecnológicas, com serviço financeiro escalável a partir da experiência do cliente, bem como estruturas operacionais enxutas, buscando o desenvolvimento, gestão ágil e marketing digital. Nessa mesma linha, Boshkov (2018) analisa se o desenvolvimento financeiro amplia as oportunidades econômicas, partindo do pressuposto de que a inclusão financeira gera benefícios potenciais de acesso aos serviços financeiros pela população. Ademais, percebe-se que alguns bancos não estão preparados para essa mudança, devido 
ao seu rígido regulamento. Isso se deve ao fato de que os bancos possuem altos padrões regulatórios, os quais oferecem mais segurança e redução de riscos.

Sendo assim, mesmo com indícios de que o oferecimento de novas tecnologias e ferramentas inovadoras podem mudar o sistema financeiro, otimizando a segurança e o estilo da população ao utilizar as FinTechs, cabe ressaltar que tais companhias podem oferecer riscos ao sistema financeiro e consequentemente afetar a economia, pois são vistas como companhias mais "ousadas" que as IF tradicionais. Além disso, conforme evidenciado, há uma carência de pesquisas sobre o tema GR na atuação das FinTechs. Esses fatores destacam-se como relevantes para a realização dessa pesquisa, tendo em vista o impacto e o reflexo das FinTechs na economia e a lacuna empírica quanto aos estudos das FinTechs na área contábil, principalmente no que diz respeito ao GR.

Diante disto, o presente estudo tem o seguinte problema de pesquisa: Quais as evidências da prática do gerenciamento de resultados nas FinTechs brasileiras? Sendo assim, define-se como objetivo de pesquisa analisar as evidências da prática do gerenciamento de resultados nas FinTechs brasileiras, no período de 2009 a 2017. Optou-se pelo período a partir de 2009 devido a crise econômica do Subprime, ocorrida em 2008, o que poderia enviesar as análises.

Desta forma, ao analisar a possivel existência da prática de GR nas FinTechs brasileiras, este trabalho contribui para a melhor compreensão sobre o comportamento oportunista dos gestores, principalmente em empresas startups que atuam com inovações tecnológicas. Além disso, a relevância do estudo demonstra evidências sobre a gestão das FinTechs, contribuindo assim para os agentes, investidores, gestores, reguladores, entre outros, que atuam no sistema financeiro.

Além desta Introdução, o trabalho apresenta o referencial teórico, com os principais conceitos de qualidade da informação contábil, gerenciamento de resultados e de FinTechs. Na seção três são apresentados os procedimentos metodológicos, posteriormente a análise dos resultados e por fim, as considerações finais.

\section{REFERENCIAL TEÓRICO}

A qualidade da informação contábil representa circunstâncias diferenciadas para cada tipo de usuário das demonstrações financeiras e está sujeita às condições do ambiente econômico, político e social. De forma complementar, a qualidade da informação contábil se modifica conforme as necessidades dos usuários das demonstrações financeiras (DECHOW; SCHRAND, 2004). Na Tabela 1 é possível verificar as proxies da qualidade da informação, que de acordo com Dechow, Ge e Schrand (2010), foram sistematizadas em três categorias. 


\begin{tabular}{|c|c|}
\hline 1) Propriedade dos resultados & $\begin{array}{l}\text { - Persistência dos resultados; } \\
\text { - Processo de modelagem dos accruals normais e anormais; } \\
\text { - Suavização dos resultados; } \\
\text { - Reconhecimento assimétrico e pontual de perdas (conservadorismo e oportunidade); e } \\
\text { - Cumprimento das metas. }\end{array}$ \\
\hline $\begin{array}{l}\text { 2) Reação dos investidores aos } \\
\text { resultados }\end{array}$ & $\begin{array}{l}\text { - Uso de modelos com significância do retorno/lucro como proxy: } \\
\text { - de qualidade dos resultados; } \\
\text { - para a qualidade do auditor e da governança. }\end{array}$ \\
\hline $\begin{array}{l}\text { 3) Indicadores externos de erros } \\
\text { nos resultados }\end{array}$ & $\begin{array}{l}\text { - Controles internos fracos; } \\
\text { - Regulação; } \\
\text { - Republicações. }\end{array}$ \\
\hline
\end{tabular}

Fonte: Elaborada a partir de Dechow, Ge, Schrand (2010).

A literatura apresenta diferentes categorias como proxy para caracterizar a qualidade da informação contábil, além das categorias evidenciadas na Tabela 1. As características das companhias, no que diz respeito ao seu desempenho, crescimento, investimento, tamanho e endividamento, são consideradas como fatores determinantes da qualidade da informação contábil. Ainda, se destacam as práticas dos relatórios financeiros, com ênfase nos métodos contábeis, nos princípios e nas estimativas. Também são considerados como determinantes: a governança, os controles, os auditores, o incentivo do mercado de ações e os fatores externos relacionados. Ressalta-se que esses fatores variam de acordo com a realidade que cada companhia apresenta e isso interfere nos determinantes de uma informação contábil útil (DECHOW; GE; SCHRAND, 2010).

Dentre as diversas dimensões da qualidade da informação contábil destaca-se o Gerenciamento de Resultados (GR), que está relacionado às decisões oportunistas tomadas pelos gestores das companhias. O GR pode ser definido como a manipulação intencional na elaboração das informações financeiras, as quais serão fornecidas aos seus usuários. Essa "manipulação" é entendida como uma intenção de atingir ganhos exclusivos (SCHIPPER, 1989). A modificação intencional nos resultados contábeis tem por finalidade atender aos objetivos particulares, onde os gestores modificam os resultados contábeis e com isso acabam não representando a imagem da companhia de forma fidedigna (MARTINEZ, 2001). Assim, o GR busca interferir nas informações contábeis de forma intencional, o que pode afetar a análise do comportamento da empresa. As práticas oportunistas podem ocorrer por meio de escolhas contábeis ou por meio de variações nas atividades operacionais habituais da empresa (PAULO, 2007).

No ambiente das Instituições Financeiras (IF), o GR se intensifica nos modelos de accruals específicos, concentrado especialmente, na análise do comportamento de Provisões para Perdas de Crédito (PPC). 
Verifica-se, ainda, a possibilidade de manipulação dos resultados por meio da classificação e mensuração do valor justo dos Títulos e Valores Mobiliários (DANTAS et al., 2013).

A prática do GR por meio de PPC é o principal mecanismo utilizado pelos gestores, por tanto, na presente pesquisa aborda-se o GR neste accrual específico das IF. A discricionariedade está relacionada ao reconhecimento das provisões e é neste ponto que pode ocorrer a subjetividade na classificação da PPC, que consequentemente pode ocasionar possíveis manipulações nos resultados (JIN; KANAGARETNAM; LOBO, 2016).

De acordo com a Resolução CMN nº 2.682 (1999) as provisões devem ser estabelecidas ao final de cada mês e não devem se inferiores ao total dos percentuais exigidos por esta, conforme evidenciado na Tabela 2.

Tabela 2 - Classificação das Operações de Crédito

\begin{tabular}{cccc}
\hline & Percentual & Classificação de Risco & Atraso no Pagamento de Parcela \\
\hline 1 & $0,50 \%$ & Nível A & - \\
\hline 2 & $1,00 \%$ & Nivel B & entre 15 e 30 dias \\
\hline 3 & $3,00 \%$ & Nivel C & entre 31 e 60 dias \\
\hline 4 & $10,00 \%$ & Nivel D & entre 61 e 90 dias \\
\hline 5 & $30,00 \%$ & Nivel E & entre 91 e 120 dias \\
\hline 7 & $50,00 \%$ & Nivel $F$ & entre 121 e 150 dias \\
\hline 8 & $70,00 \%$ & Nivel G & entre 151 e 180 dias \\
\hline
\end{tabular}

Fonte: Elaborada a partir de Resolução CMN n² 2.682, 1999.

É importante salientar que a subjetividade na definição dos níveis de risco para a classificação da PPC viabiliza possível discricionariedade aos gestores, onde os mesmos podem utilizá-las como prática para GR (CARVALHO; PEREIRA; DANTAS, 2018). Ainda que existam percentuais mínimos estabelecidos pela Resolução CMN n 2.682 (1999), os gestores das companhias podem aplicar percentuais superiores, buscando suavizar os resultados.

Deste modo, nas pesquisas de GR em IF, como a de Modena (2017), analisa-se há relação entre a baixa da taxa Selic ocorrida em 2011 e 2012 e a utilização dos accruals discricionários pelos bancos que atuam no Brasil. Como resultados, foi evidenciado que os momentos de queda nos resultados não discricionários, podem ter sido percebidos em situações de menor dinamismo econômico.

Por outro lado, Peterson e Arun (2018) apresentam como objetivo analisar se a forma como os bancos sistêmicos suavizam os resultados por meio de Provisões para Perdas de Crédito (PPC), diferem dos 
bancos não sistêmicos. Os autores evidenciam que os bancos sistêmicos apresentaram maior suavização de resultados via PPC durante os períodos de recessão e na presença de empréstimos inadimplentes.

No estudo de Sousa e Bressan (2018), os autores analisaram se há indícios de que as instituições financeiras brasileiras, de pequeno e grande porte, aplicam o gerenciamento de resultados buscando evitar a divulgação de prejuízos, no período de 2008 a 2015. Os resultados demonstram que há indícios de gerenciamento de resultados nos bancos de pequeno porte, o que evita a divulgação de prejuízos em todos os períodos analisados. Por outro lado, nos bancos de grande porte não foi possível detectar indícios de gerenciamento de resultados na mesma modalidade.

No mesmo sentido, Macedo e Kelly (2016) em sua pesquisa, objetivaram verificar se existem indícios de gerenciamento de resultados nas instituições financeiras operantes no Brasil, através da utilização das Provisões para Perdas de Crédito (PPC), foi considerado o período de 2006 a 2012, para os bancos com capital estrangeiro. Como resultados, apresentam que o gerenciamento de resultados é utilizado com mais frequência em bancos com capital estrangeiro, por meio da PPC. Por outro lado, os bancos com capital nacional apresentam uma relação menos frequente de gerenciamento de resultados por meio da PPC.

A partir destas pesquisas realizadas no contexto das IF, é possivel perceber que há uma tendência à apresentação de resultados contábeis melhores e/ou com menor volatidade como prática de GR. Isso demonstra que a prática de GR é utilizada pelos gestores para a eficiência das companhias e não para fins oportunistas, o que consequentemente proporciona menor interesse aos reguladores do sistema financeiro - BACEN.

No entanto, as FinTechs (Financial Technologys) estão ganhando cada vez mais força no ambiente financeiro, considerando que as transformações digitais e o potencial de tecnologia estão sendo explorados e maximizados em alta escala. A chamada "era da FinTech" enfatiza que as IF necessitam da elaboração de um plano claro, buscando a eficácia na adaptação e nos benefícios gerados pelas FinTechs. Ao mesmo tempo em que o setor bancário é naturalmente mais conservador quanto às mudanças, as mudanças rápidas envolvem novas tecnologias e com isso propagam novas soluções (BOSHKOV, 2018).

Neste sentido, o Brasil se tornou atrativo para a realização de investimentos em FinTechs, desde que concedam recursos inovadores. Levando em consideração que a maior parte da população não possui aproximação com os serviços financeiros, tal atrativo se justifica pela forte concentração do mercado, do spread bancário elevado, aumento de tarifas pelos serviços e expectativa de inovação regulatória (PwC, 2018).

Por meio do uso intensivo de tecnologia, as FinTechs se caracterizam como empresas que proporcionam inovações tecnológicas nos mercados financeiros, intensificando a constituiç̧ão de novos 
modelos de negócios. As FinTechs são categorizadas no ambiente internacional da seguinte maneira: de pagamento, compensação e liquidação, depósito, empréstimo e levantamento de capital, financiamento, e gestão de investimentos. E no cenário brasileiro, são classificadas nas seguintes categorias: de pagamento, gestão financeira, empréstimo, investimento, financiamento, seguro, negociação de dívidas, criptoativos e Distributed Ledger Technologies (DLT), câmbio, e multisserviços (BACEN, 2018).

As FinTechs de crédito são caracterizadas como IF que concedem e intermediam operações de crédito às pessoas físicas e jurídicas. As IF que concedem crédito são as empresas que atuam em operações com seus próprios recursos, através de meios eletrônicos. Por outro lado, as IF que intermediam empréstimos entre pessoas, operam como intermediários entre credores e devedores, através de negociações por meios eletrônicos (BACEN, 2018).

As modalidades de FinTechs de crédito existentes, segundo a Resolução do Conselho Monetário Nacional (CMN) n 4.656 (2018), são: a Sociedade de Crédito Direto (SCD) e a Sociedade e Empréstimo entre Pessoas (SEP). Denominada de instituição financeira, a SCD apresenta como objeto a atuação em operações de empréstimo, de financiamento e de aquisição de direitos creditórios, sendo de forma exclusiva através de plataforma eletrônica e atendendo à disposição de que os recursos financeiros sejam provenientes especificamente de capital próprio. No entanto, a SEP é configurada como uma instituição financeira que tem por objeto a intermediação de operações de empréstimo e de financiamento entre pessoas, de forma restrita ao uso de plataforma eletrônica (BACEN, 2018). Então, a diferença básica entre SCD e SEP é a forma de atuação nas operações de empréstimos e financiamentos, e a origem dos recursos financeiros, que na SCD é através de capital próprio e na SEP é através da intermediação de recursos de terceiros.

Esse segmento de startups elabora inovações tecnológicas no ambiente financeiro e por isso potencializam ameaças à três entre cada quatro bancos, ou seja, aproximadamente $76 \%$ das IF. As ameaças ocorrem pelo fato de que as FinTechs se destacam pelo seu atendimento ao consumidor, oferecendo meios diferenciados de comunicação e flexibilizam a obtenção de empréstimos e pagamentos. De forma eficiente, elas desenvolvem soluções altamente aplicáveis ao observar o que os bancos oferecem ou deixam de oferecer e com isso se destacam em termos de serviços ofertados (PwC, 2016).

Porém, muitas destas startups, obtém recursos financeiros de investidores-anjo. Essa contribuição mostra-se significativa para as companhias, tanto na visão dos investidores quanto das startups. As principais contribuições consistem em: aportes financeiros, mentorias e suportes com rede de contatos, além de outros auxílios, como espaço físico para trabalho e feedbacks sobre o projeto. Esses recursos fornecidos pelos investidores-anjo possibilitam maior visibilidade para as startups no mercado (MENGUE; SCHMIDT; BOHNENBERGER, 2019). 
A ausência de visibilidade no mercado mostra-se como um ponto predominante na dificuldade de obtenção de capital. Fato este, que ainda restringe o impacto das FinTechs na economia. Outro agravante para os negócios do setor é a situação econômica e a política, que se apresenta instável. Além da burocracia, alta carga tributária e a complexidade da legislação tributária brasileira (PwC, 2018).

Dentre as pesquisas existentes que abordem as FinTechs, destaca-se a de Boshkov (2018), que analisa se o desenvolvimento financeiro amplia as oportunidades econômicas, partindo do pressuposto que a inclusão financeira gera benefícios potenciais de acesso aos serviços financeiros pela população. Como principais resultados, é demonstrado que alguns bancos não estão suficientemente preparados para essa mudança, devido ao seu rígido regulamento. Mas, altos padrões regulatórios significam que os bancos oferecem mais segurança e redução de riscos. Oferecer novas tecnologias e ferramentas inovadoras pode mudar o sistema financeiro, otimizando a segurança e o estilo da população ao utilizálas.

No estudo de Barbosa (2018) buscou-se examinar a forma de atuação das FinTechs no ambiente financeiro, foram realizadas entrevistas com 11 FinTechs de diferentes segmentos e 3 empresas do ecossistema das empresas. Como principais resultados, evidencia-se que na atuação das FinTechs são utilizadas principalmente bases tecnológicas, com serviço financeiro escalável baseado na experiência do cliente, assim como estruturas operacionais enxutas, buscando o desenvolvimento, gestão ágil e marketing digital.

Na pesquisa de Ferreira et al. (2019), por exemplo, buscaram compreender as evoluções de novos modelos de negócios no mercado financeiro em relação ao crédito, a partir das três maiores FinTechs e identificar o comportamento dos clientes diante dos novos modelos. Apresentou-se como resultados que os clientes têm respondido de forma positiva aos novos modelos de negócios, com um aumento considerável de usuários e um curto espaço de tempo, enquanto os bancos tradicionais, com agências físicas, expressam indícios de redução de clientes.

Diante dos estudos abordados, salienta-se que as FinTechs buscam oferecer ferramentas inovadoras e novas tecnologias para otimizar a experiência de seus clientes. Porém, essas ferramentas podem interferir no sistema financeiro e econômico do país, pois as IF (Não FinTechs) apresentam padrões regulatórios rígidos, são mais conservadoras e consequentemente oferecem mais segurança e redução de riscos. Sendo assim, tenciona-se verificar se há relação entre o GR e as FinTechs, ou seja, se há evidências da prática de GR pelos gestores destas FinTechs. Com isso define-se a Hipótese 1 (H1): Há evidências da prática do gerenciamento de resultados nas FinTechs brasileiras. 


\section{PROCEDIMENTOS METOdOLÓGICOS}

Nessa seção são apresentados os procedimentos metodológicos adotados para a pesquisa. Primeiramente definindo a classificação metodológica, em seguida apresentando a população, a amostra e o procedimento de coleta de dados e por fim demonstrando os modelos estatísticos utilizados na pesquisa.

O presente estudo se classifica como quantitativo, descritivo e documental. No que diz respeito à abordagem do problema, a pesquisa é definida como quantitativa, pois o tratamento dos dados passa estritamente por técnicas estatísticas. No processo de desenvolvimento da pesquisa, o método quantitativo busca classificar a relação entre as variáveis para garantir a precisão dos resultados, dessa forma evitando distorções nas interpretações (PRODANOV; FREITAS, 2013).

Com relação aos objetivos, essa pesquisa é caracterizada como descritiva, pois busca registrar e descrever observações, com a finalidade de explicar e interpretar os fatos ocorridos. A pesquisa descritiva tem por finalidade, principalmente, descrever as características de uma população ou fenômeno específico, estabelecendo vínculo entre as variáveis (GIL, 2012).

Quanto aos procedimentos, define-se como pesquisa documental, por utilizar-se de coleta e organização de informações advindas de documentos sem tratamento analítico. A pesquisa documental opera com documentos como fonte de dados, informações e evidências, através de fontes primárias, as quais ainda não foram utilizadas em análises (MARTINS; THEÓPHILO, 2016).

\subsection{POPULAÇÃO, AMOSTRA E COLETA DE DADOS}

O Banco Central do Brasil - BACEN - classifica as instituições em oito tipos: Bancos, Cooperativas de Crédito, Administradores de Consórcios, Sociedades de Créditos e afins, Conglomerados Financeiros, Conglomerados Prudenciais, Combinados Cooperativos, Instituições em Regime Especial. A população utilizada nessa pesquisa é composta pelas companhias que apresentam as demonstrações financeiras no site do Banco Central do Brasil ao final do exercício de 2017, especificamente as companhias classificadas no seguinte tipo de instituição, conforme demonstrado na Tabela 3. 
Tabela 3 - Tipo de instituição

\begin{tabular}{lc}
\hline \multicolumn{1}{c}{ Tipo de instituição } & Quantidade de Companhias em 2017 \\
\hline Sociedades corretoras de títulos e valores mobiliários e câmbio & 132 \\
\hline Sociedades distribuidoras de títulos e valores mobiliários & 94 \\
\hline Sociedades de crédito, financiamento e investimento & 56 \\
\hline Sociedades de crédito imobiliário & 1 \\
\hline Associações de poupança e empréstimo & 1 \\
\hline Companhias hipotecárias & 7 \\
\hline Sociedades de arrendamento mercantil & 23 \\
\hline Agências de fomento & 16 \\
\hline Sociedades de crédito ao microempreendedor e à empresa de pequeno porte & 38 \\
\hline Instituições de pagamento & 6 \\
\hline TOTAL & 374 \\
\hline
\end{tabular}

Fonte: Elaborada a partir de Banco Central do Brasil (2018).

É possivel verificar na Tabela 3 que, ao final do exercício de 2017, totalizam-se 374 companhias com informações financeiras disponíveis no BACEN, para a população estabelecida. Para selecionar a amostra, foi definida a utilização das instituições que apresentaram saldos na rubrica: 1.6.9.00.00-8 (Provisões para operações de crédito, neste estudo denominada de Provisões para Perdas de Créditos), que em 2017 totalizam 114 companhias.

Após a seleção da amostra, foram constituídos dois grupos de instituições, um denominado de FinTechs, onde foram alocadas as sociedades de créditos, com base na Resolução do Conselho Monetário Nacional - CMN n 4.656 (2018) e o outro grupo denominado de Não FinTechs, onde foram distribuídas as demais instituições. Na Tabela 4, são apresentados esses dois grupos. 
Tabela 4 - Grupos de amostra

\begin{tabular}{lclc}
\hline \multicolumn{1}{c}{ Grupo FinTechs } & Quantidade em 2017 & Grupo Não FinTechs & Quantidade em 2017 \\
\hline $\begin{array}{l}\text { Sociedades de crédito, financiamento e } \\
\text { investimento }\end{array}$ & 53 & Agências de fomento & 16 \\
\hline $\begin{array}{l}\text { Sociedades de crédito ao microempreen- } \\
\text { dedor e à empresa de pequeno porte }\end{array}$ & 35 & Companhias hipotecárias & 6 \\
\hline $\begin{array}{l}\text { Sociedades de crédito imobiliário } \\
\text { TOTAL }\end{array}$ & 1 & $\begin{array}{l}\text { Sociedades corretoras de } \\
\text { títulos e valores mobiliários } \\
\text { e câmbio }\end{array}$ & 2 \\
\hline
\end{tabular}

Fonte: Elaborada a partir de dados da pesquisa (2019).

Cabe destacar que no grupo de Não FinTechs ainda fazem parte as Sociedades de Arrendamento Mercantil, as Instituições de Pagamento e as Sociedades Distribuidoras de Títulos e Valores Mobiliários, porém não foram utilizadas para a amostra desta pesquisa, pois não apresentaram saldo na rubrica de Provisões para Perdas de Crédito. A coleta de dados ocorreu no site do BACEN, utilizando as demonstrações contábeis anuais, do período de 2009 a 2017. Optou-se pelo período, pois optou-se em analisar o período após a crise econômica do Subprime de 2008, o que poderia enviesar as análises.

\subsection{DESCRIÇÃO DO MODELO OPERACIONAL}

Nessa pesquisa utilizou-se regressão linear múltipla com dados em painel. As informações trimestrais referentes aos saldos das contas contábeis foram coletadas no site BACEN e as informações do PIB foram coletadas no site do Instituto Brasileiro de Geografia e Estatística - IBGE -, conforme a Tabela 5. 


\section{Gestãoe \\ Desenvolvimento}

Tabela 5 - Variáveis

\begin{tabular}{|c|c|c|c|c|}
\hline Variável & Sigla & Descrição & Código & Autores \\
\hline Dependente & PPC & $\begin{array}{c}\text { Provisões Perdas de Crédito / } \\
\text { Ativo Total }\end{array}$ & $\begin{array}{l}1.6 .9 .00 .00-8 \\
3.9 .9 .99 .99-3\end{array}$ & \multirow{2}{*}{$\begin{array}{l}\text { Peterson e Arun (2018), } \\
\text { Macedo e Kelly (2016), } \\
\text { Sousa e Bressan (2018). }\end{array}$} \\
\hline Independente & EBTP & $\begin{array}{l}\text { Lucros antes de impostos e pro- } \\
\text { visões perdas / Ativo Total }\end{array}$ & $\begin{array}{l}\text { 8.9.0.00.00-7 } \\
3.9 .9 .99 .99-3\end{array}$ & \\
\hline Independente & CAR & $\begin{array}{c}\text { Capital de Nivel } 1=\mathrm{PL} / \text { ativos } \\
\text { ponderados pelo risco }\end{array}$ & $\begin{array}{l}6.0 .0 .00 .00-2 \\
3.1 \cdot 0.00 .00-0 \\
\end{array}$ & $\begin{array}{l}\text { Peterson e Arun (2018), } \\
\text { Sousa e Bressan (2018). }\end{array}$ \\
\hline Independente & NPL & $\begin{array}{l}\text { Provisões Perdas de Crédito / } \\
\text { Crédito Bruto Operações }\end{array}$ & $\begin{array}{l}1.6 .9 .00 .00-8 \\
1.6 .0 .00 .00-1 \\
\end{array}$ & \multirow{2}{*}{$\begin{array}{l}\text { Peterson e Arun (2018), } \\
\text { Sousa e Bressan (2018). }\end{array}$} \\
\hline Independente & VPPC & $\begin{array}{c}\text { Variação de PPC / Crédito Bruto } \\
\text { Operações }\end{array}$ & $\begin{array}{l}1.6 .9 .00 .00-8 \\
1.6 .0 .00 .00-8 \\
\end{array}$ & \\
\hline Independente & LSIZE & Logaritmo natural Ativo Total & 3.9.9.99.99-3 & $\begin{array}{l}\text { Peterson e Arun (2018), } \\
\text { Sousa e Bressan (2018). }\end{array}$ \\
\hline VPIB & - & Variação Trimestral do PIB & Controle & Peterson e Arun (2018). \\
\hline
\end{tabular}

Fonte: Elaborada a partir de dados da pesquisa (2019).

Aplicou-se o modelo de regressão adaptado de Peterson e Arun (2018) e de acordo com estudos já realizados sobre o tema. Conforme demonstrado na Tabela 5, o modelo de regressão pode ser verificado a seguir na Equação 1.

Equação 1:

$P P C_{i t}=\beta_{0}+\beta_{1} E B T P_{i t}+\beta_{2} C A R_{i t}+\beta_{3} N P L_{i t}+\beta_{4} V P P C_{i t} t+\beta_{5 L} S I Z E_{i t}+\beta_{6 L} V P I B_{i t}+\varepsilon_{i t}$ Eq (1)

Em que:

$P P C_{i t}=$ Total das Provisões para Perdas de Crédito ponderado pelo Ativo Total do banco ino trimestre $t$

$E B T P_{i t}=$ Lucros antes de impostos e provisões para perdas ponderados pelo ativo total do banco $i$ no trimestre $t$;

$C A R_{i t}=$ Relação de Capital de Nível 1 dividido pelo total de ativos ponderados pelo risco do banco $i$ no trimestre $t$;

$N P L_{i t}=$ Relação da Provisão para Perdas de Crédito sobre o crédito bruto do banco $i$ no trimestre $t$;

$V P P C_{i t}=$ Variação das Provisões para Perdas de Crédito do banco $i$ no trimestre $t_{\text {; }}$

$L S I Z E_{i t}=$ Logaritmo natural do Ativo Total do banco ino trimestre $t$;

$V P I B_{t}=$ Taxa real de crescimento do produto interno bruto do trimestre $t-1$ para o trimestre $t ;$

$\varepsilon_{i t}=$ erro da estimação. 
Com base na literatura sobre o tema, espera-se um sinal negativo e significativo para o coeficiente de $E B T P$, indicando que a possibilidade de ocorrência da prática de gerenciamento de resultados diminui quando há crescimento nos lucros antes de impostos e provisões para perdas. Para o coeficiente CAR, espera-se apresentar um sinal negativo e significativo, indicando que os bancos buscam manter $P P C$ mais altas quando apresentam CAR baixo e com isso compensando o seu capital regulatório.

Para o coeficiente $N P L$, a presença de um sinal positivo e significativo, indica que no momento em que se esperam maiores perdas de créditos reais, há um possivel aumento nas provisões específicas. No coeficiente $V P P C$, espera-se obter um sinal negativo e significativo, evidenciando que a redução nas Provisões para Perdas de Crédito indica que possivelmente ocorra a prática de gerenciamento de resultados. Espera-se para o coeficiente $L S I Z E$, um sinal negativo e significativo, sugerindo que os bancos maiores não necessariamente apresentam gerenciamento de resultados mais frequentes do que nos bancos menores.

Por fim, para o coeficiente VPIB, espera-se obter um sinal negativo e significativo, pois com o aumento do PIB é possível identificar um bom desempenho da economia e dessa forma indicando que a prática do gerenciamento de resultados por meio das provisões tende a ser menor. De forma complementar, evidencia-se a Equação 2, que inclui uma variável dummy para identificar as companhias FinTechs $\left(F_{i t}\right)$ e a inclusão de duas interações com cada variável independente, também para capturar o comportamento diferente entre as FinTechs e as não FinTechs.

Equação 2:

$P P C_{i t}=\beta_{0}+\beta_{1} E B T P_{i t}+\beta_{2} C A R_{i t}+\beta_{3} N P L_{i t}+\beta_{4} V P P C_{i t} t+\beta_{5} L S I Z E_{i t}+\beta_{6} V P I B_{i t}+\beta_{7} F_{i t}+\varepsilon_{i t}$ Eq (2)

Assim, é possível verificar o comportamento das companhias denominadas FinTechs e Não FinTechs e de modo semelhante comparar os resultados entre as sub amostras com a amostra geral da pesquisa.

\section{ANÁLISE DOS RESULTADOS}

\subsection{ESTATÍSTICA DESCRITIVA}

Na Tabela 6 é possível analisar a estatística descritiva das variáveis utilizadas para a estimação dos accruals discricionários, utilizou-se o modelo estatístico adaptado de Peterson e Arun (2018). As análises foram segregadas por grupos de análise - Geral, Não Fintechs e Fintechs. O número de observações apresentado na Tabela 6 corresponde às observações de companhia/trimestre. 
Tabela 6 - Estastística Descritiva

\begin{tabular}{|c|c|c|c|c|c|c|}
\hline & $P P C$ & EBTP & CAR & NPL & VPPC & LSIZE \\
\hline \multicolumn{7}{|l|}{ Painel A - Geral } \\
\hline observações & 1028 & 1028 & 1028 & 1028 & 1028 & 1028 \\
\hline Média & 0,0736 & 0,0227 & 2,4482 & 0,1749 & 1,2038 & 17,6829 \\
\hline desvio-padrão & 0,0890 & 0,0866 & 6,3418 & 0,2438 & 4,0391 & 2,9273 \\
\hline Mediana & 0,0427 & 0,0138 & 0,6560 & 0,0847 & 0,2523 & 17,9841 \\
\hline Mínimo & 0,0001 & $-0,3163$ & 0,0002 & 0,0035 & $-0,9644$ & 12,2271 \\
\hline Máximo & 0,4873 & 0,3104 & 40,6550 & 1,5086 & 30,9537 & 24,1642 \\
\hline \multicolumn{7}{|c|}{ Painel B - Não FinTechs } \\
\hline observações & 213 & 213 & 213 & 213 & 213 & 213 \\
\hline Média & 0,0276 & 0,0066 & 4,3077 & 0,1052 & 1,1915 & 19,1121 \\
\hline desvio-padrão & 0,0316 & 0,0212 & 8,0353 & 0,1705 & 4,1741 & 1,7706 \\
\hline Mediana & 0,0170 & 0,0068 & 1,3824 & 0,0595 & 0,2969 & 19,2940 \\
\hline Mínimo & 0,0001 & $-0,0485$ & 0,0002 & 0,0035 & $-0,9644$ & 15,4097 \\
\hline Máximo & 0,2246 & 0,0821 & 40,6550 & 1,5086 & 30,9537 & 22,7163 \\
\hline \multicolumn{7}{|c|}{ Painel C - FinTechs } \\
\hline observações & 815 & 815 & 815 & 815 & 815 & 815 \\
\hline Média & 0,0856 & 0,0269 & 1,9622 & 0,1931 & 1,2070 & 17,3094 \\
\hline desvio-padrão & 0,0950 & 0,0962 & 5,7258 & 0,2566 & 4,0057 & 3,0529 \\
\hline Mediana & 0,0544 & 0,0195 & 0,5219 & 0,0959 & 0,2449 & 17,5500 \\
\hline Mínimo & 0,0001 & $-0,3163$ & 0,0002 & 0,0035 & $-0,9644$ & 12,2271 \\
\hline Máximo & 0,4873 & 0,3104 & 40,6550 & 1,5086 & 30,9537 & 24,1642 \\
\hline
\end{tabular}

Fonte: Elaborada a partir de dados da pesquisa (2019). $* * *$, ${ }^{* *} e^{*}$, significantes ao nivel de $1 \%, 5 \%$ e $10 \%$, respectivamente.

No Painel A da Tabela 6, a variável EBTP para a amostra Geral, apresenta uma média positiva $(0,0227)$ indicando que, em média, as companhias utilizam o gerenciamento de resultados, possivelmente, quando apresentam melhores resultados antes de impostos e provisões para perdas. A média de EBTPestá similar ao encontrado no estudo de Modena (2017), da mesma forma que o desvio-padrão (0,0866). Nos Painéis B e C, que se referem às amostras de Não FinTechs e FinTechs, a variável EBTP apresenta uma média mais alta nas IF FinTechs $(0,0269)$ do que nas Não FinTechs $(0,0066)$. Isso sugere que, possivelmente, as FinTechs 
apresentam maior tendência a prática de GR por meio de PPC, do que as companhias Não FinTechs, considerando o período desta pesquisa.

Com o teste $W$ de Shapiro-Wilk foi possivel verificar que as variáveis desta pesquisa não seguem uma distribuição normal. Sendo assim, procedeu-se uma análise da correlação de Spearman, conforme a apresentada na Tabela 7.

Tabela 7 - Análise de Correlação de Spearman

\begin{tabular}{lllllll}
\hline \multicolumn{1}{c}{ LLP } & EBTP & CAR & NPL & VPPC & LSIZE & VPIB \\
\hline PPC & 1 & & & & & \\
\hline EBTP & $0.0918^{* * *}$ & 1 & & & & \\
\hline CAR & $-0.1776^{* * *}$ & $-0,0461$ & 1 & & & \\
\hline NPL & $0.7944^{* * *}$ & $-0,0474$ & 0,0375 & 1 & 1 & \\
\hline VPPC & $0.0846^{* * *}$ & 0,0223 & $-0.0707^{* *}$ & $-0,0105$ & 1 \\
\hline LSIZE & $-0,0604^{*}$ & $-0,0604^{*}$ & $-0.3709^{* * *}$ & $-0,0559^{*}$ & $-0.0909^{* * *}$ & 1 \\
\hline VPIB & $-0,0293$ & 0,0289 & $-0,0165$ & $-0,0415$ & $-0.1228^{* * *}$ & 0,0261 \\
\hline
\end{tabular}

Fonte: Elaborada a partir de dados da pesquisa (2019).

$* * *{ }^{* *} e^{*}$, significantes ao nivel de $1 \%, 5 \%$ e $10 \%$, respectivamente.

A partir da Tabela 7, é possivel verificar que há uma correlação negativa entre a variável CAR e a variável $\operatorname{VPPC}(-0,0707)$, o que indica que à medida em que aumenta (diminui) o Capital de Nivel 1, a variação das Provisões para Perdas de Crédito tende a diminuir (aumentar). Ainda, pode ser destacado que existe uma correlação positiva entre a variável VPPC e PPC $(0,0846)$, indicando que a variação das Provisões para Perdas de Crédito aumenta (diminui) à medida em que o total das provisões aumenta (diminui). Cabe destacar, que a correlação de EBTPe $P P C$ demonstrou-se positiva e significativa $(0,0918)$, isso sugere que as provisões tendem a aumentar à medida em que os resultados das companhias também aumentam.

Ao que se refere à significância das correlações, apenas a variável VPIB não apresentou relação significativa com a variável dependente $(P P C)$, demostrando que, o aumento do PIB não pode ser visto como um parâmetro que explica o gerenciamento de resultados por meio de PPC, diferentemente do esperado. Pois, nos estudos de Peterson e Arun (2018), a suavização de resultados foi mais pronunciada entre os bancos sistêmicos no período pós-crise.

\subsection{ANÁLISE DE REGRESSÃO}

Para verificar se há evidências da prática de GR pelos gestores das companhias - FinTechs e Não FinTechs -, realizaram-se as estimações conforme as Equações 1 e 2, que estão apresentadas na Tabela 
8. Na primeira coluna - Geral (1) - encontram-se as estimações da Equação 1, com base em todas as companhias da amostra, a fim de identificar a possível existência da prática de GR da amostra geral. Nas colunas (2) e (3), respectivamente, são apresentadas as estimações para as amostras das FinTechs e Não FinTechs, com o intuito de comparar o possivel comportamento oportunista desses dois grupos de companhias. Por fim, na coluna (4) - Dummy FinTech - é apresentada a estimação dos parâmetros para a Equação 2, na qual inclui uma variável para identificar as companhias FinTechs $\left(F_{i t}\right)$ e as duas interações propostas, também para capturar o comportamento diferente entre FinTechs e Não FinTechs.

Buscando tratar os casos outliers desta amostra, utilizou-se a técnica de winsorização das variáveis, que objetiva "aparar" os casos extremos, tanto para cima quanto para baixo. Inicialmente, apresentam-se os resultados para as duas equações na Tabela 8.

Tabela 8 - Análise de Regressão

\begin{tabular}{|c|c|c|c|c|}
\hline & $\begin{array}{c}\text { Geral } \\
\text { (1) }\end{array}$ & $\begin{array}{l}\text { FinTech } \\
\text { (2) }\end{array}$ & $\begin{array}{l}\text { Não FinTech } \\
\text { (3) }\end{array}$ & $\begin{array}{c}\text { Dummy FinTech } \\
\text { (4) }\end{array}$ \\
\hline Constante & $-0,123^{*}$ & $-0,119$ & $-0,099$ & $-0,115$ \\
\hline EBTP & $-0,155^{* * *}$ & $-0,156^{* * *}$ & $-0,136^{*}$ & $-0,136$ \\
\hline CAR & 0,000 & 0,000 & $-0,000$ & $-0,000$ \\
\hline NPL & $0,152^{* * *}$ & $0,155^{* * *}$ & $0,109^{* * *}$ & $0,109^{* * *}$ \\
\hline VPPC & $0,001^{*}$ & $0,001^{* *}$ & $-0,000$ & $-0,000$ \\
\hline LSIZE & $0,010^{* *}$ & $0,010^{* *}$ & 0,006 & 0,006 \\
\hline VPIB & $-0,001^{* *}$ & $-0,001^{*}$ & $-0,000$ & $-0,000$ \\
\hline $\mathrm{F}$ & & & & 0,000 \\
\hline FEBTP & & & & $-0,020$ \\
\hline FCAR & & & & 0,000 \\
\hline FNPL & & & & 0,047 \\
\hline FVPPC & & & & $0,001^{*}$ \\
\hline FLSIZE & & & & 0,004 \\
\hline FVPIB & & & & $-0,001$ \\
\hline Observações & 1.028 & 815 & 213 & 1.028 \\
\hline$R^{2}$ & 0,330 & 0,331 & 0,494 & 0,335 \\
\hline $\mathrm{R}^{2}$ ajustado & 0,183 & 0,182 & 0,369 & 0,183 \\
\hline F test & 69,116 & 54,942 & 27,637 & 35,063 \\
\hline
\end{tabular}

Fonte: Elaborada a partir de dados da pesquisa (2019).

$* * *{ }^{* *} e^{*}$, significantes ao nivel de $1 \%, 5 \%$ e $10 \%$, respectivamente. 
Conforme observado na Tabela 8, o lucro antes de impostos e provisões para perdas (EBTP) apresentou coeficiente negativo e significativo para as três primeiras estimações (Geral, FinTechs e Não FinTechs). Esses resultados sugerem que a Provisão para Perdas de Créditos (PPC) das companhias (FinTechs ou Não FinTechs) no período analisado, em média, tem comportamento inverso a variável EBTP, ou seja, quando há um aumento (redução) no lucro antes de impostos e provisões para perdas, as companhias apresentam uma tendência à redução (aumento) no volume de Provisão para Perdas de Créditos. Isso sugere que, possivelmente, ocorra a prática de GR nessas companhias em períodos de resultados contábeis menores, o que indica que as provisões podem ser utilizadas para eficiência e não para fins oportunistas, para a amostra dessa pesquisa. Esse resultado está de acordo com o esperado, corroborando o estudo de Modena (2017), onde foi evidenciado que os momentos de queda nos resultados não discricionários, podem ter sido percebidos em situações de menor dinamismo econômico. Já no modelo da Equação 2, com a variável dummy $\mathrm{F}$ e as suas interações, o EBTP apresentou-se negativo, porém não significativo.

De acordo com a Tabela 8, a relação de Capital de Nivel 1 (CAR) - ativos ponderados pelo risco -, não se mostrou significativa para explicar o comportamento da Provisão para Perdas de Créditos ( $P P C$ ), para todas as amostras. Já a variável $N P L$, que representa a relação da PPC sobre o crédito bruto, se mostrou positiva e significativa para todas as estimações, a um nível de 1\%, inclusive para o modelo da Equação 2. Esse resultado apresenta indícios de que as companhias tendem a reportar saldos de PPC maiores em períodos de expectativas de maiores créditos inadimplentes. Consequentemente, os gestores buscam amenizar os riscos de crédito, controlando-os de forma mais rigorosa e isso pode proporcionar a prática da suavização de resultados nessas companhias.

A variação das Provisões para Perdas de Crédito (VPPC) se mostrou significativa somente para a estimação da amostra Geral (1) e para a amostra das FinTechs (2), ao nivel de 10\% e 5\% respectivamente. Apesar dessa variável ser estatisticamente significativa, a um nível de 5\%, o seu coeficiente não é economicamente significativo para explicar o comportamento da Provisão para Perdas de Créditos e da possível existência de GR. Já para a amostra de Não Fintechs e para a dummy F, os coeficientes se mostraram negativos, porém não significativos.

As variáveis $L S I Z E$ (tamanho) e VPIB (taxa real de crescimento do produto interno bruto) demonstraram coeficientes significativos e negativos para as estimações com a amostra Geral e das FinTechs. Para a amostra de Não FinTechs e dummy F, os coeficientes foram positivos, porém não significativos. Cabe destacar, que a variável de interação $\left(F_{i t}\right)$ e as variáveis de interação não foram significativas para a Equação 2.

Observa-se que a amostra relacionada às instituições Não FinTechs apresentou melhor ajustamento para estimação do $P P C$ e com um $R^{2}$ ajustado de 0,369, o que sugere que o modelo está adequado à esta 
amostra. O $R^{2}$ demonstra o quanto a variável dependente ( $\left.P P C\right)$ é explicada pelas variáveis independentes, considerando a quantidade de variáveis e o tamanho da amostra. Os resultados da regressão apresentaram alto valor explicativo, mas resultados semelhantes a este foram encontrados em pesquisas como a de Dantas et al. (2013) com um $R^{2}$ ajustado de 0,395. Assim, sugere-se que o alto coeficiente de determinação dessa pesquisa não inviabiliza o uso do modelo proposto.

De forma geral, os resultados dessa pesquisa comportaram-se conforme o esperado, corroborando os estudos de Elnahass, Izzeldinb e Steeleb (2018) e Lassoued, Attia e Sassi (2018), indicando que possivelmente ocorra a prática de GR com o uso de PPC pelas FinTechs. E mesmo que ocorra a prática de GR pelos gestores destas companhias, a prática pode estar sendo utilizada para fins de eficiência das companhias e não para fins oportunistas. Ainda, destaca-se que os resultados estão de acordo com a pesquisa de Peterson e Arun (2018), sugerindo que as companhias Não FinTechs tendem a adotar medidas para a prática de GR menores do que as FinTechs analisadas, isso pode ser explicado pelo fato de que as mesmas tendem a ser menos "ousadas", assim buscam conter a volatidade nos seus resultados e despertando menor interesse pelos reguladores.

\subsection{ANÁLISE DE SENSIBILIDADE}

Buscando verificar se há evidências da prática de GR pelos gestores das companhias classificadas como FinTechs e Não FinTechs, nesta seção são apresentados os resultados das equações sem a winsorização dos dados da amostra.

A pesquisa foi realizada com as estimações conforme as Equações 1 e 2, e estão apresentadas na Tabela 9. Na primeira coluna (1), foi estimada a Equação 1 com base na amostra geral das companhias, a fim de identificar a discricionariedade. Nas colunas (2) e (3), respectivamente, são apresentadas as estimações para as amostras das FinTechs e Não FinTechs, buscando comparar o comportamento oportunista desses dois grupos de companhias. Por fim, na coluna (4) é apresentada a estimação dos parâmetros para a Equação 2, na qual inclui uma variável para identificar as companhias FinTechs $\left(F_{i t}\right)$ e as duas interações, também para capturar o comportamento diferente entre FinTechs e Não FinTechs. 
Tabela 9 - Análise de Regressão

\begin{tabular}{|c|c|c|c|c|}
\hline & $\begin{array}{l}\text { Geral } \\
\text { (1) }\end{array}$ & $\begin{array}{l}\text { FinTech } \\
\text { (2) }\end{array}$ & $\begin{array}{l}\text { Não FinTech } \\
\text { (3) }\end{array}$ & $\begin{array}{c}\text { Dummy FinTech } \\
\text { (4) }\end{array}$ \\
\hline Constante & $-0,149^{* *}$ & $-0,139^{* *}$ & $-0,090$ & $-0,129^{* *}$ \\
\hline EBTP & $-0,107^{* * *}$ & $-0,092^{* * *}$ & $-0,140^{*}$ & $-0,140$ \\
\hline CAR & $-0,000$ & $-0,000$ & $-0,000$ & $-0,000$ \\
\hline NPL & $0,229^{* * *}$ & $0,249^{* * *}$ & $0,110^{* * *}$ & $0,110^{* * *}$ \\
\hline VPPC & $0,001^{* *}$ & $0,001^{* * *}$ & $-0,000$ & $-0,000$ \\
\hline LSIZE & $0,010^{* * *}$ & $0,010^{* * *}$ & 0,006 & 0,006 \\
\hline VPIB & $-0,001^{* * *}$ & $-0,001^{* *}$ & $-0,000$ & $-0,000$ \\
\hline $\mathrm{F}$ & & & & 0,000 \\
\hline FEBTP & & & & 0,048 \\
\hline FCAR & & & & 0,000 \\
\hline FNPL & & & & $0,139^{* * *}$ \\
\hline FVPPC & & & & $0,002^{*}$ \\
\hline FLSIZE & & & & 0,005 \\
\hline FVPIB & & & & $-0,001$ \\
\hline Observações & 1.090 & 852 & 238 & 1.090 \\
\hline$R^{2}$ & 0,491 & 0,513 & 0,489 & 0,512 \\
\hline $\mathrm{R}^{2}$ ajustado & 0,379 & 0,404 & 0,363 & 0,400 \\
\hline F test & 135,477 & 116,765 & 27,137 & 73,087 \\
\hline
\end{tabular}

Fonte: Elaborada a partir de dados da pesquisa (2019).

$* * *,{ }^{* *} e *$, significantes ao nivel de 1\%,5\% e 10\%, respectivamente.

Na análise da Tabela 9 é possível verificar que o lucro antes de impostos e provisões para perdas (EBTP) apresenta coeficiente negativo e significativo para as estimações da amostra Geral (-0.107), de FinTech (-0.092) e de Não FinTech (-0.140). Tais resultados possibilitam entender que em média a Provisão para Perdas de Créditos ( $P P C$ ) das companhias (FinTechs ou Não FinTechs) para o período analisado, se comportam de forma inversa a variável EBTP, ou seja, em situações de aumento (redução) nos lucros antes de impostos e provisões para perdas, as companhias tendem a apresentar uma redução (aumento) no volume destas Provisões. O resultado evidenciado está diferente do esperado, visto que Araújo, Lustosa e Paulo (2018) apresentaram que a variável EBTP se revelou significativa para instituições financeiras 
espanholas, o que sugere que não existem evidências de práticas de gerenciamento de resultados com a provisão para perdas de crédito pelos bancos espanhóis. Esse resultado pode ser explicado pelo motivo de que o ambiente econômico espanhol é distinto do brasileiro. Para o modelo da Equação 2, com a variável dummy $F_{i t}$ e as suas interações, o $\operatorname{EBTP}(0,000)$ não se mostrou significativo.

No que diz respeito à relação de Capital de Nivel $1(C A R)$ - ativos ponderados pelo risco - os coeficientes se mostraram negativos, porém não significativos $(-0,000)$ para explicar o comportamento da Provisão para Perdas de Créditos ( $P P C)$, para todas as amostras. Por outro lado, a relação da PPC sobre o crédito bruto, representada pela variável NPL, se mostrou positiva e significativa para todas as estimações (Geral: 0,229; FinTechs: 0,249; Não FinTechs: 0,110), a um nivel de 1\%, inclusive para o modelo da Equação 2. Esse resultado sugere que, possivelmente, as companhias tendem a reportar saldos de PPC com valores mais elevados em situações que a expectativa é de créditos inadimplentes também com valores maiores. Desta forma, os gestores tencionam conter os riscos de créditos de forma mais rigorosa, o que consequentemente possibilita a ocorrência do GR. Esses resultados estão de acordo com os resultados de Jin, Kanagaretnam e Lobo (2016), sugerindo que os gestores destas companhias tendem a utilizar das Provisões para Perdas de Crédito para a eficiência dos resultados das companhias e não somente para fins oportunistas.

É possível verificar que a variação das Provisões para Perdas de Crédito (VPPC) se mostrou positiva e significativa somente para a estimação com amostra Geral $(0,001)$ e de FinTechs $(0,001)$, ao nível de 5\% e $1 \%$, respectivamente. Mesmo que a variável tenha se mostrado estatisticamente significativa, a um nível de $1 \%$, o seu coeficiente não é economicamente significativo para explicar o comportamento das Provisões para Perdas de Créditos. No que diz respeito às variáveis $L S I Z E$ (tamanho) e VPIB (taxa real de crescimento do produto interno bruto), as mesmas se mostraram positivas e significativas para as estimações com a amostra Geral e das FinTechs, ao nível de 1\%.

Destaca-se que a amostra de companhias classificadas como FinTechs demonstrou melhor ajustamento à estimação da variável $P P C$, com um $R^{2}$ ajustado de 0,404. O $R^{2}$ ajustado representa o quanto a variável dependente $(P P C)$ é explicada pelas independentes, considerando a quantidade de variáveis e o tamanho da amostra. Nesta análise, sugere-se que o modelo é adequado à amostra desta pesquisa, considerando os outliers. 0 alto valor explicativo destes resultados também foi encontrado em pesquisas como Zainuldin e Lui (2018), com $R^{2}$ ajustado de 0,4453. Sendo assim, indica-se que o alto coeficiente de determinação desse estudo não inviabiliza o uso do modelo proposto.

Portanto, os resultados dessa pesquisa estão de acordo com o esperado e corroboram a pesquisa de Peterson e Arun (2018), sugerindo que as companhias classificadas como FinTechs apresentam tendência à utilização de maior suavização de resultados por meio de Provisões para Perdas de Créditos, em 
situações créditos inadimplentes. Ainda, os resultados sugerem que prática de GR pelos gestores, pode ser utilizada para fins de eficiência da companhia, buscando apresentar melhores resultados dentro do GAAP normativo e, não necessariamente utilizada para fins oportunistas. As companhias FinTechs apresentam mais indícios da prática de GR em relação às Não FinTechs, esse fato pode ser explicado pela adoção de ferramentas mais "ousadas" pelas companhias FinTechs, o que consequentemente oferece maior risco para o ambiente econômico e o sistema financeiro. Por fim, destaca-se que os resultados dessa pesquisa não apresentaram evidências empíricas suficientes para rejeitar $H 1$, de que existem evidências da prática do gerenciamento de resultados nas FinTechs brasileiras, com isso rejeita-se $\mathrm{HO}$.

\section{CONSIDERAÇõES FINAIS}

Essa pesquisa teve como objetivo analisar as evidências da prática do gerenciamento de resultados nas FinTechs brasileiras, no período de 2009 a 2017. A escolha do período a partir de 2009 deu-se pela ocorrência da crise econômica do Subprime, no ano de 2008, a utilização dos dados deste ano poderia enviesar as análises.

Como resultados para este estudo, pode ser destacado que, possivelmente, existam evidências da prática de gerenciamento de resultados pelos gestores das companhias classificadas como FinTechs, por meio do uso das Provisões para Perdas de Créditos. A ocorrência da prática de gerenciamento de resultados por estas companhias pode estar sendo utilizada para eficiência da companhia, onde os gestores buscam conter a volatidade dos resultados contábeis, o que consequentemente tende a despertar menor interesse pelos reguladores e, portanto, destaca-se que esta prática nem sempre é realizada com propósitos oportunistas.

De modo geral, as companhias classificadas como FinTechs demonstram maior tendência à utilização da prática de gerenciamento de resultados em relação às companhias Não FinTechs, por meio da suavização dos resultados ao utilizar das Provisões para Perdas de Créditos nas situações de créditos inadimplentes. Essa maior evidência da prática de gerenciamento de resultados pelas FinTechs pode ser justificada pela adoção de ferramentas tecnológicas inovadoras e "ousadas", o que consequentemente oferece maior risco para o ambiente econômico e para o sistema financeiro. As companhias Não FinTechs, por possuírem controles mais rígidos e por serem consideradas mais "conservadoras", tendem a oferecer riscos menores ao sistema financeiro. Sendo assim, destaca-se que os resultados dessa pesquisa não apresentaram evidências empíricas suficientes para rejeitar $H 1$, de que existem evidências da prática do gerenciamento de resultados nas FinTechs brasileiras, com isso rejeita-se $\mathrm{HO}$. 
Os resultados estão em conformidade com os achados nas pesquisas de Elnahass, Izzeldinb e Steeleb (2018) e Lassoued, Attia e Sassi (2018), que sugerem que possivelmente ocorra a prática de gerenciamento de resultados com o uso de Provisões para Perdas de Créditos em companhias que oferecem riscos ao sistema financeiro, mesmo que seja para fins de eficiência da companhia. Ainda, cabe destacar que os resultados corroboram a pesquisa de Peterson e Arun (2018), sugerindo que as companhias Não FinTechs apresentam menor tendência de adoção de prática de gerenciamento de resultados do que as FinTechs analisadas, buscando conter a volatidade nos seus resultados.

Desta forma, este estudo contribui para o meio profissional demonstrando aos diversos usuários das informações, principalmente aqueles que atuam no sistema financeiro, melhor compreensão sobre uma possivel prática do GR pelos gestores, em particular, aqueles que atuam em empresas startups e com inovações tecnológicas. A pesquisa contribui para o mercado, no sentido de demonstrar aos acionistas que as escolhas legais feitas pelos gestores não prejudicam os resultados divulgados. A divulgação da prática do GR pelas IF demonstra aos acionistas que, em situações onde as escolhas são feitas de forma legal, a prática de GR não é vista como prejudicial à companhia. Além disso, essa pesquisa auxilia no aperfeiçoamento das regras do sistema financeiro, ao divulgar possíveis práticas oportunistas nessas companhias.

Ainda, destaca-se que a presente pesquisa contribui para o meio acadêmico, no que diz respeito às pesquisas sobre o tema de Gerenciamento de Resultados em Instituições Financeiras, tendo em vista que não foram identificadas pesquisas que abordem a prática do GR em FinTechs brasileiras. No geral, os resultados sugerem que possivelmente ocorra a prática de GR nessas companhias em períodos de resultados contábeis menores, o que indica que as provisões podem ser utilizadas para eficiência da companhia e não necessariamente para fins oportunistas.

Esta pesquisa limita-se ao período de análise (2009 a 2017), bem como às FinTechs brasileiras e ainda se limita à aplicação do modelo de Peterson e Arun (2018). Para estudos futuros, sugere-se a inclusão de outras variáveis ao modelo de regressão, que abordem fatores econômicos relacionados à prática do gerenciamento de resultados, a inclusão de um período maior e consequentemente mais observações. 


\section{REFERÊNCIAS}

ARAÚJO, A.; LUSTOSA, P.; PAULO, E. A ciclicidade da provisão para créditos de liquidação duvidosa sob três diferentes modelos contábeis: Reino Unido, Espanha e Brasil. Revista Contabilidade \& Finanças, v. 29, n. 76, p. 97-113, abr. 2018. Disponivel em: http://www.revistas.usp.br/rcf/article/view/141339. Acesso em: 12 dez. 2018.

BACEN. Banco Central do Brasil. Perguntas frequentes. Disponível em: https://www.bcb.gov.br/pre/ bc_atende/port/fintechs.asp?idpai=faqcidadao. Acesso em: 12 dez. 2018.

BARBOSA, R. R. Fintechs: a atuação das empresas de tecnologia de serviço financeiro no setor bancário e financeiro brasileiro. 2018. 129 f. Dissertação (Mestrado Profissional em Administração), Escola de Administração, Programa de Pós-graduação em Administração, Universidade Federal do Rio Grande do Sul, Porto Alegre, RS, 2018. Disponível em: https://www.lume.ufrgs.br/handle/10183/178364. Acesso em: 29 set. 2018.

BOSHKOV, T. Level of deepening financial infrastructure, fintech companies and financial inclusion: theory and evidence. International Journal of Information, Business and Management, v. 10, n. 4, p. 21-29, nov. 2018. Disponível em: http://eprints.ugd.edu.mk/20272/. Acesso em: 24 out. 2018.

BRASIL. Conselho Monetário Nacional. Resolução n 2.682, de 1999. Dispõe sobre critérios de classificação das operações de crédito e regras para constituição de provisão para créditos de liquidação duvidosa, Brasilia, DF, dez. 1999. Disponível em: https://www.bcb.gov.br/pre/normativos/res/1999/pdf/ res_2682_v2_L.pdf. Acesso em: 12 dez. 2018.

BRASIL. Conselho Monetário Nacional. Resolução n 4.656, de 2018. Dispõe sobre a sociedade de crédito direto e a sociedade de empréstimo entre pessoas, Brasilia, DF, abr. de 2018. Disponível em: https:// www.bcb.gov.br/pre/normativos/busca/downloadNormativo.asp?arquivo=/Lists/Normativos/Attachments/50579/Res_4656_v1_0.pdf. Acesso em: 29 out. 2018.

CARVALHO, J. A.; PEREIRA, J. V.; DANTAS, J. A. As Instituições Financeiras Brasileiras Usam a PCLD para Gerenciamento de Capital? Enfoque: Reflexão Contábil, v. 37, n. 2, p. 127-140, jun. 2018. Disponível em: http://periodicos.uem.br/ojs/index.php/Enfoque/article/view/34077. Acesso em: 12 out. 2018.

DANTAS, J. et al. Gerenciamento de resultados em bancos com uso de TVM: validação de modelo de dois estágios. Revista Contabilidade \& Finanças, v. 24, n. 61, p. 37-54, abr. 2013. Disponivel em: http://www. revistas.usp.br/rcf/article/view/58649. Acesso em: 24 out. 2018. 
DECHOW, P. M.; GE, W.; SCHRAND, C. Understanding earnings quality: a review of the proxies, their determinants and their consequences. Journal of Accounting and Economics, v. 50, n. 1, p. 344-401, dec. 2010. Disponivel em: https://repository.upenn.edu/accounting_papers/124/. Acesso em: 23 out. 2018.

DECHOW, P.; SCHRAND, C. Earnings quality. Virginia: CFA Institute, 2004. 160 p. Disponivel em: https:// www.cfainstitute.org/research/foundation/2004/earnings-quality. Acesso em: 30 out. 2018.

ELNAHASS, M.; IZZELDINB, M.; STEELEB, G. Capital and Earnings Management: Evidence from Alternative Banking Business Models. International Journal of Accounting, v. 53, n. 1, p. 20-32, feb. 2018. Disponivel em: https:/www.sciencedirect.com/science/article/abs/pii/S0020706318300475. Acesso em: 12 dez. 2018.

FERREIRA, C. A. et al. Novas evoluções do mercado de crédito: uma análise sobre as fintechs. Revista de Iniciação Científica da Universidade Vale do Rio Verde, Três Corações, v. 9, n. 1, p. 79-89, 2019. Disponivel em: http://periodicos.unincor.br/index.php/iniciacaocientifica/article/view/5221. Acesso em: 22 out. 2019.

GIL, A. C. Métodos e técnicas de pesquisa social. 6. ed. São Paulo: Atlas, 2012.

JIN, J.; KANAGARETNAM, K.; LOBO, G. J. Discretion in bank loan loss allowance, risk taking and earnings management. Accounting \& Finance, v. 58, n. 1, p. 171-193, mar. 2016. Disponivel em: https://www. sciencedirect.com/science/article/abs/pii/S2214635018302375?via\%3Dihub. Acesso em: 15 nov. 2018.

LASSOUED, N.; ATTIA, M. B. R.; SASSI, H. Earnings management in islamic and conventional banks: Does ownership structure matter? Evidence from the MENA region. Journal of International Accounting, Auditing and Taxation, v. 30, n. 1, p. 85-105, mar. 2018. Disponivel em: https://www.sciencedirect.com/ science/article/abs/pii/S1061951817300721. Acesso em: 15 nov. 2018.

MACEDO, M. A. S.; KELLY, V. L. A. Gerenciamento de resultados em instituições financeiras no brasil uma análise com base em provisões para crédito de liquidação duvidosa. Revista Evidenciação Contábil \& Finanças, v. 4, n. 2, p. 82-96, 2016. Disponivel em: https://periodicos.ufpb.br/index.php/recfin/article/ view/29260. Acesso em: 16 nov. 2018.

MARTINEZ, A. L. Gerenciamento dos resultados contábeis: estudo empírico das companhias abertas brasileiras. 2001. 124 f. Tese (Doutorado em Contabilidade e Controladoria) - Curso de Pós-graduação em Contabilidade e Controladoria, Faculdade de Economia, Administração e Contabilidade, Universidade de São Paulo, São Paulo, SP, 2001. Disponivel em: http://www.teses.usp.br/teses/disponiveis/12/12136/tde-14052002-110538/publico/tde.pdf. Acesso em: 20 jan. 2019. 
MARTINS, G. A.; THEÓPHILO, C. R. Metodologia da investigação científica para ciências sociais aplicadas. 3. ed. São Paulo: Atlas, 2016.

MENGUE, T. H. S.; SCHMIDT, S.; BOHNENBERGER, M. C. Contribuições do investimento anjo para o desenvolvimento de startups na região metropolitana de Porto Alegre. Revista Gestão e Desenvolvimento, v. 16, n. 1, p. 71-98, 2019. Disponivel em: https://periodicos.feevale.br/seer/index.php/revistagestaoedesenvolvimento/article/view/1640. Acesso em: 10 ago. 2021.

MODENA, J. L. Gerenciamento de resultados nos bancos: uma análise das Políticas de redução de juros. 2017. 66 f. Dissertação (Mestrado em Contabilidade) - Curso de Pós-Graduação em Contabilidade, Universidade Federal do Paraná, Curitiba, PR, 2017. Disponivel em: https://acervodigital.ufpr.br/bitstream/ handle/1884/49394/R\%20-\%20D\%20-\%20JOSE\%2OLUIS\%20MODENA.pdf?sequence=1\&isAllowed=y. Acesso em: 10 fev. 2019.

PAULO, E. Manipulação das informações contábeis: uma análise teórica e empírica sobre os modelos operacionais de detecção de gerenciamento de resultados. 2007. Tese (Doutorado em Controladoria e Contabilidade) - Curso de Pós-graduação em Controladoria e Contabilidade, Faculdade de Economia, Administração e Contabilidade, Universidade de São Paulo, São Paulo, 2007. Disponivel em: https://www. teses.usp.br/teses/disponiveis/12/12136/tde-28012008-113439/pt-br.php. Acesso em: 12 dez. 2018.

PETERSON, O.; ARUN, T. Income smoothing among European systemic and non-systemic banks. The British Accounting Review, v. 50, n. 5, p. 539-558, sep. 2018. Disponivel em: https://www.sciencedirect. com/science/article/abs/pii/S0890838918300210. Acesso em: 02 out. 2018.

PRODANOV, C. C.; FREITAS, E. C. de. Metodologia do trabalho científico: métodos e técnicas da pesquisa e do trabalho acadêmico. 2. ed. Novo Hamburgo: Feevale, 2013. 276 p. Disponível em: http://www. feevale.br/Comum/midias/8807f05a-14d0-4d5b-b1ad-1538f3aef538/E-book\%20Metodologia\%20 do\%20Trabalho\%20Cientifico.pdf. Acesso em: 12 nov. 2018.

PwC. PricewaterhouseCoopers. Pesquisa da PwC aponta que 76\% das instituições bancárias se sentem ameaçadas pelo avanço das FinTechs, 2016. Disponível em: https://www.pwc.com.br/pt/sala-de-imprensa/noticias/76-instituicoes-bancarias-sentem-ameacadas-avanco-FinTechs.html. Acesso em: 12 out. 2018.

Pwc. PricewaterhouseCoopers. Pesquisa Fintech Deep Dive 2018. Disponivel em: https://www.pwc. com.br/pt/setores-de-atividade/financeiro/2018/pub-fdd-18.pdf. Acesso em: 20 dez. 2018.

SCHIPPER, K. Commentary on earnings management. Accounting Horizons, v. 3, n. 1, p. 91-102, 1989. 


\section{Gestãoe \\ Desenvolvimento}

e-ISSN: 2446-6875

p-ISSN: $1807-5436$

SOUSA, L. O.; BRESSAN, V. G. F. Gerenciamento de Resultados em Bancos: Indícios relacionados à aversão a divulgação de prejuízos. Revista Evidenciação Contábil \& Finanças, v. 6, n. 1, p. 83-100, 2018. Disponivel em: http://www.spell.org.br/documentos/ver/48623/gerenciamento-de-resultados-em-bancos--indicios-relacionados-a-aversao-a-divulgacao-de-prejuizos-. Acesso em: 16 dez. 2018.

ZAINULDIN; M. H.; LUI, T. K. Earnings management in financial institutions: A comparative study of Islamic banks and conventional banks in emerging markets. Pacific-Basin Finance Journal, v. 1, n. 1, p. 1-49, jul. 2018. Disponivel em: https://www.sciencedirect.com/science/article/pii/S0927538X17303372. Acesso em: 16 dez. 2018. 